\title{
Monocyte-T Lymphocyte Interaction for Regulation of Insulin Receptors on the Activated T Lymphocyte
}

\author{
J. H. Helderman, R. Ayuso, J. Rosenstock, and P. Raskin \\ Department of Internal Medicine, The University of Texas Health Science Center \\ at Dallas, Southwestern Medical School, Dallas, Texas 75235
}

\begin{abstract}
During activation the lymphocyte attains functional insulin receptors with precise regulation, a consequence of insulin concentration manipulations. These studies test the hypothesis that insulin receptor $(+)$ monocytes monitor insulin concentrations, so instructing the $T$ lymphocytes. Monocyte-enriched populations were incubated with insulin $\left(0-10^{-6} \mathrm{M}\right)$ followed by co-culture with $\mathbf{T}$ lymphocytes and an activating stimulus. A dose-related fall in $\mathbf{T}$ lymphocyte insulin receptor binding was observed that was specific for the monocyte as the signalling cell and for insulin as the signal received. Monocytes from normal volunteers during a euglycemic, hyperinsulinemic clamp were cultured with $T$ lymphocytes and an activating stimulus. A decline in specific insulin receptor binding on $\mathbf{T}$ lymphocytes was observed, which Scatchard analysis demonstrated to be a consequence of reduction in receptor numbers. These studies demonstrate that the receptor $(+)$ monocyte perceives the concentration of insulin and passes this information to $T$ lymphocytes regulating the number of activation-induced insulin receptors. The interplay between the monocyte and $T$ lymphocyte parallels the interaction of these cell types for recognition of antigen.
\end{abstract}

\section{Introduction}

Antigens initiate the expansion of unique clones of reactive lymphocytes. During this activation event, the cell attains a spectrum of surface molecules, activation markers, most of which subserve a receptor function for specific ligands (1-6). Not only do these surface molecules mark the activation event, but they also bear a temporal relationship with the stages of lymphocyte activation (7). More importantly, the receptor function of these activation markers is frequently permissive or regulatory for the full expression of lymphocyte activation $(1,3,7)$. Although antigen stimulation may provide an on-off signal for the ultimate display of these activation markers, finer regulation of the number of such receptors can be observed.

This laboratory has been concerned with understanding the immunobiology of the activation marker, the insulin receptor, and has delineated both the marker function and binding func-. tion of this unique molecule (4-6). Moreover, one can show that there is indeed precise regulation of the numbers of this activation marker, a consequence of manipulation of either chronic or acute ambient insulin concentrations in human sub-

These studies were presented in part at the National Meeting of The American Society for Clinical Investigation, May 1985.

Address reprint requests to Dr. Helderman. 1986.

Received for publication 4 March 1986 and in revised form 20 October

J. Clin. Invest.

(c) The American Society for Clinical Investigation, Inc.

0021-9738/87/02/0566/06 \$1.00

Volume 79, February 1987, 566-571 jects $(8,9)$. Alterations of in vivo insulin concentrations by fasting or long-term insulin infusions were accompanied by regulation of the numbers of lymphocyte insulin receptors in a manner which suggested that the ambient insulin concentration was the regulatory signal which had to be perceived by the insulin receptor-negative lymphocyte and remembered in tissue culture where lymphocyte activation stimuli were supplied and insulin receptor synthesis was effected. Additionally, acute manipulation of ambient insulin during the euglycemic, hyperinsulinemic clamp further supported the concept that ambient insulin is the regulatory signal perceived by circulating, receptor-negative $T$ lymphocytes and remembered in tissue culture.

In several other model systems, ligand-directed regulation of specific receptor display is, at least in great part, a consequence of the binding event itself. Because chronic or acute alterations in ambient insulin are effected at a time when quiescent $T$ lymphocytes do not bear detectable surface insulin receptors, the mechanism by which the ligand concentration is perceived to produce a regulatory signal is unknown. Recently, this laboratory has shown that the activated helper $\mathrm{T}$ lymphocyte is permissive for the generation of B lymphocyte insulin receptors in a manner very similar to that by which the helper $T$ lymphocyte is permissive for antigen processing and recognition for controlling quantitatively antibody response of the B cell (10). Afferent recognition of many antigens requires initial processing by circulating and/or tissue-fixed cells of the monocyte-macrophage lineage. The insulin receptor on these cells is constitutive, and thus potentially capable of reading the ambient insulin concentration in a manner that permits these afferent signals to be passed from the monocyte to the receptor-negative $T$ lymphocyte.

The purpose of this study, then, is to test the hypothesis that the insulin receptor-positive circulating monocyte is capable of instructing the quiescent insulin receptor-negative $T$ lymphocyte as to the ambient concentration of insulin, the consequence of which will be a down-regulation of antigen-driven $T$ lymphocyte insulin receptor display.

\section{Methods}

\section{In vitro studies}

The goal of the in vitro studies was to test the effect of incubation of isolated monocytes from rat spleen with various insulin concentrations, followed by mixing with $\mathrm{T}$ lymphocytes in tissue culture. On day 0 (Fig. 1), a highly enriched monocyte preparation was obtained from Lewis male rat spleen. Spleens were teased over steel mesh into RPMI 1640 buffered with $10 \mathrm{mM}$ Hepes and enriched with $1 \%$ fetal calf serum (insulin deplete) and placed atop a Ficoll-Hypaque density gradient. The mononuclear cell fraction was preserved from the density gradient and prepared for nylon wool filtration as previously described (4). For monocyte enrichment, $10^{8}$ unseparated mononuclear cells were placed upon preincubated columns containing $2.4 \mathrm{~g}$ of washed nylon wool in a $20-\mathrm{ml}$ sterile syringe. After a $45-\mathrm{min}$ incubation at $37^{\circ} \mathrm{C}$ in a $5 \% \mathrm{CO}_{2}: 5 \%$ air environment, the columns were washed with $100 \mathrm{ml}$ of RPMI 1640 containing 5\% fetal calf serum. Monocytes, along with other nylon wool adherent cellular elements, were then obtained by disruption of the re- 


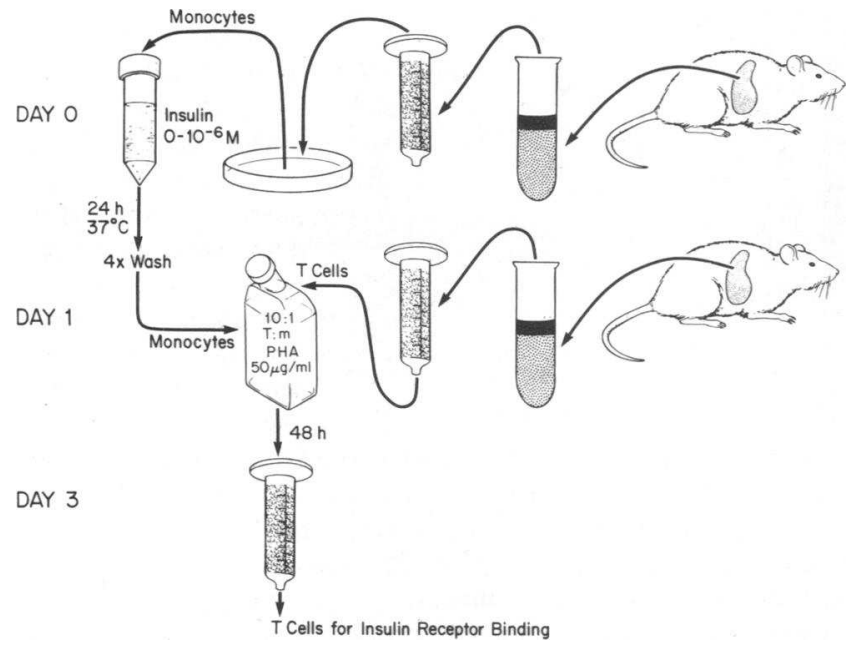

Figure 1. Graphic description of the protocol used for the in vitro study of monocyte-T cell lymphocytes interaction for insulin receptor display on activated $\mathrm{T}$ lymphocytes.

maining nylon wool into an additional $50 \mathrm{ml}$ of complete medium. The resultant nylon wool adherent cell population was pelleted at 2,500 rpm for 10 min (Beckman Instruments, Inc., Fullerton, CA) and resuspended in $20 \mathrm{ml}$ of the medium at $20 \times 10^{6} / \mathrm{ml}$. These $20 \mathrm{ml}$ were introduced onto a glass petri dish (140 mm diam) followed by incubation for 60 min at $37^{\circ} \mathrm{C}$. At the completion of the incubation, the plate was swirled and the nonsticking cells were aspirated with a pipette. The plates were then washed with 2 vol phosphate-buffered saline (PBS) followed by an incubation with a $3 \mathrm{rd}$ volume of $\mathrm{PBS}$ at $4^{\circ} \mathrm{C}$ for $30 \mathrm{~min}$. At the completion of the incubation, the glass dish adherent cells were obtained by scraping the dish with a rubber-tipped spatula followed by two further washes with PBS.

This population was $>99 \%$ monocyte enriched as determined by cytofluorographic analysis of monoclonal antibodies to monocyte markers. The monocytes were placed at $20 \times 10^{6}$ cells in $5 \mathrm{ml}$ of buffered RPMI 1640 enriched with 5\% insulin-depleted fetal calf serum in 10-ml tissue culture tubes (Nunc-Inter Med, Roskilde, Denmark) along with a varying final concentration of insulin $\left(0-10^{-6} \mathrm{M}\right)$ for incubation for 24 $h$ at $37^{\circ} \mathrm{C}$ in an atmosphere of $5 \% \mathrm{CO}_{2}$ :air. On day 1 a T-enriched population was obtained from the nylon wool nonadherent fraction after two consecutive columns as previously described (4). This population was $>95 \% \mathrm{~T}$ enriched (cytofluorography) (Fig. 2) and contained virtually no measureable monocytes. When the monocyte precultures had completed $24 \mathrm{~h}$ of contact with insulin, the cultures were extensively washed, the cells placed at $10^{6} / \mathrm{ml}$ in complete media containing $5 \%$ fetal calf serum (insulin deplete), and then co-mixed with the freshly prepared syngeneic $\mathrm{T}$ lymphocytes at a final ratio of $10 \mathrm{~T}$ lymphocytes/1 monocyte. Present in each 20 -ml culture were $10^{7} \mathrm{~T}$ lymphocytes, $10^{6}$ monocytes, buffered RPMI 1640 enriched with 5\% insulin-depleted fetal calf serum, and phytohemagglutinin-P (Difco Laboratories, Detroit, MI) at a final concentration of $50 \mu \mathrm{g} / \mathrm{ml}$. The co-mixture was incubated for a further $48 \mathrm{~h}$ at $37^{\circ} \mathrm{C}$ in the $5 \% \mathrm{Co}_{2} /$ air environment. The culture was harvested over a nylon wool column so that the effluent, T-enriched population could be collected and reserved for insulin receptor binding studies. The efficiency of the nylon wool to separate the monocytes from the lectintreated, activated lymphocytes was confirmed using cytofluorographic analysis of monocyte and $T$ lymphocyte surface markers.

To test the specificity of the monocyte-T lymphocyte interaction for regulation of activated $\mathrm{T}$ lymphocyte insulin receptor display, control studies $(n=5)$ were performed in which either B lymphocyte-enriched or $\mathrm{T}$ lymphocyte-enriched cell populations were preincubated with insulin $\left(0-10^{-6} \mathrm{M}\right)$ before co-culture with freshly prepared, syngeneic $\mathrm{T}$ lymphocyte in parallel to the above studies.

To test the specificity of insulin as the regulatory signal, monocytes

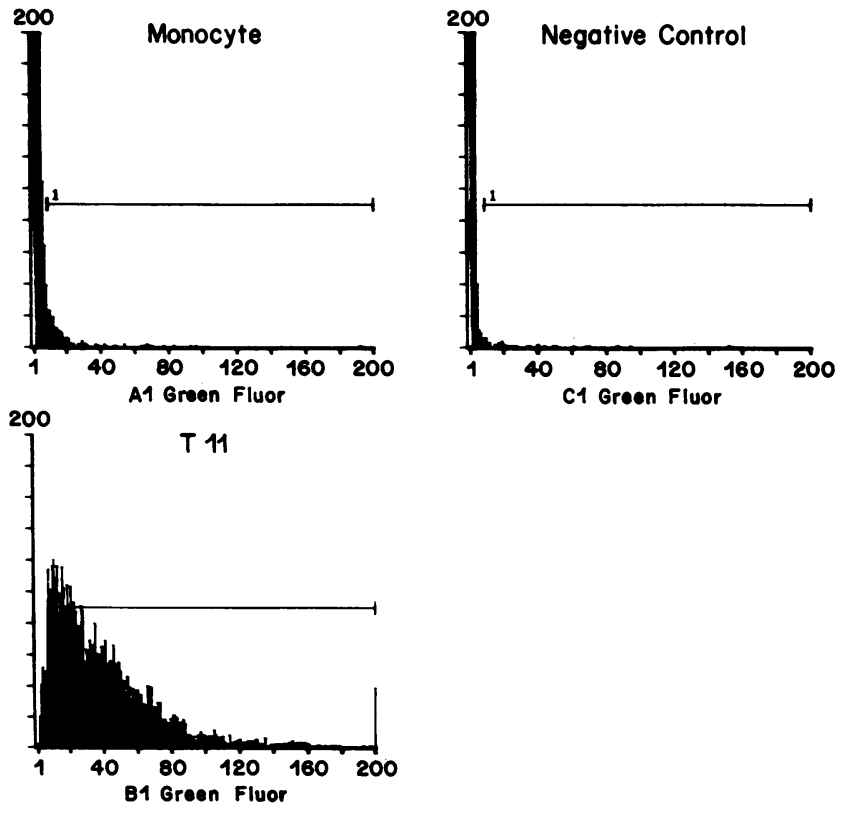

Figure 2. Fluorescein-activated cell sorter analysis of $\mathrm{T}$ enrichment protocol demonstrating monocyte staining virtually at background levels.

were preincubated with glucagon $\left(0-10^{-6} \mathrm{M}\right)$ followed by wash and coculture with freshly prepared $\mathrm{T}$ lymphocytes as above.

To test the specificity of the regulatory signal for the insulin receptor, monocytes were preincubated with insulin $\left(0-10^{-7} \mathrm{M}\right)$ followed by coculture with $\mathrm{T}$ lymphocytes, with analysis, after activation, of the presence of another activation receptor, the interleukin II receptor by cytofluorographic analysis of binding of the monoclonal antibody TAC (a gift from Dr. Peter Lipsky of this institution).

\section{Insulin-binding assay}

The insulin receptor binding assay has been reported previously and extensively characterized and validated in previous communications (4, 9-12). The nature of nonspecific binding, the form of the Scatchard relationship, the success of separation of bound from free radiolabeled insulin, and the pharmacokinetic characteristics of the T lymphocyte insulin receptor have also been described previously (4-12). It is recognized that the binding assay used here may miss measurement of a low affinity, high capacity, biologically irrelevant binding site. Enough cells were withdrawn at zero time and after $4 \mathrm{~h}$ of the clamp condition to construct complete association binding isotherms in one additional human study. For these studies, specific binding of ${ }^{125} \mathrm{I}$-iodoinsulin was measured under equilibrium binding conditions after provision of trace iodoinsulin at a final concentration of $1 \mathrm{nM}$. Similar studies were done using $\mathrm{T}$ lymphocytes and monocytes obtained from three normal weight, nondiabetic human volunteers using an identical protocol as just described to confirm the observations made with the rodent cells.

\section{In vivo studies-the euglycemic clamp}

Patient population. Seven normal weight, young male nondiabetic subjects with a mean fasting glucose concentration of $93 \pm 2 \mathrm{mg} / \mathrm{dl}$ and a mean fasting immunoreactive insulin concentration of $9 \pm 1 \mu \mathrm{U} / \mathrm{ml}$ were studied by the euglycemic, hyperinsulinemic clamp technique of DeFronzo et al. (Table I) (13). The assumptions and mathematic algorithms that underlie the performance of the euglycemic clamp have been well described and have been used by this laboratory in previous studies $(9$, $14,15)$. In brief, the subjects were studied in the Clinical Research Center of this institution after an overnight fast. Plasma glucose concentrations were maintained near or at the "euglycemic goal" by use of a negative feedback algorithm using assays of "arterialized" blood glucose measured 
every two and one-half minutes for the first $30 \mathrm{~min}$ of the study and every $5 \mathrm{~min}$ for the remainder of the 240 -min study. Blood for measurements of immunoreactive insulin was obtained at the same points. For these studies blood samples were obtained for isolation of $\mathrm{T}$ lymphocytes before the clamp $(0 \mathrm{~h})$ and for human monocytes at the $0-, 2$ and 4-h time points. The specificity of the insulin changes during the clamp on activated $\mathrm{T}$ lymphocyte insulin receptors display has previously been demonstrated by performance of 4-h sham clamps using saline to substitute for the glucose and insulin infusions (9).

Cell preparation. Standard and well-described techniques for recovering highly $\mathrm{T}$ lymphocyte-enriched cell populations from human peripheral blood lymphocytes have been described and validated by us in previous manuscripts $(4-6,9)$. In brief, the blood obtained at $0 \mathrm{~h}$ was diluted 1:3 with Hanks' balanced salt solution buffered with $10 \mathrm{mM}$ Hepes and placed on a Ficoll-Hypaque density gradient. Passage of the mononuclear cells obtained from the gradient through two consecutive nylon wool columns produces a population that is $>95 \% \mathrm{~T}$ enriched and is $>98 \%$ viable by trypan blue exclusion. Using the nylon wool separation and glass adherence techniques described above, we also obtained highly monocyte-enriched cell populations from the $0-, 2-$, and 4-h points during the clamp. Zero time $\mathrm{T}$ lymphocytes were mixed with $0-, 2-$, or 4-h monocytes at a 10:1 ratio $\left(20 \times 10^{6} \mathrm{~T}: 2 \times 10^{6}\right.$ monocytes $)$ in $30 \mathrm{ml}$ of complete media pulsed with $2.5 \mu \mathrm{g} / \mathrm{ml}$ phytohemaggiutininP. At the completion of $48 \mathrm{~h}$ of cultures at $37^{\circ} \mathrm{C}$ in a $5 \% \mathrm{CO}_{2} /$ air environment, the cultures were harvested by filtration over a nylon wool column so that the T-enriched populations could be reversed alone for analysis of insulin receptor binding.

Measurement of plasma glucose and immunoreactive insulin. The plasma glucose concentration during the clamp was measured using a glucose oxidase system on a glucose analyzer (Beckman Instruments, Inc.). Insulin was measured by the Herbert modification (16) of the assay that was originally described by Yalow and Berson (17).

\section{Results}

\section{In vitro monocyte: $T$ lymphocyte interaction}

The first series of studies tested the effect of incubation of circulating, insulin receptor-bearing monocytes with various insulin concentrations in vitro followed by mixing with $\mathrm{T}$ lymphocytes on the ability of polyclonal stimulators to generate insulin receptors on T lymphocytes. Preincubation of the monocyte-enriched populations ( $>99 \%$ ) greatly affected the ability of lectin to induce a complement of insulin receptors on $T$ lymphocytes (Fig. 3). There was a substantial and progressive reduction in activated $\mathrm{T}$ lymphocyte insulin receptor specific binding as a function of the concentration of insulin in the preincubation with monocytes alone, from $13.3 \pm 1.2 \mathrm{pg}$ of ${ }^{125}$-iodoinsulin specifically bound to $10^{6}$ lymphocytes when the preincubation environment for the monocyte did not contain insulin, to $1.7 \pm 0.5$ $\mathrm{pg} / 10^{6}$ lymphocytes when $10^{-6} \mathrm{M}$ insulin was preincubated with a monocyte. This represented a fall to a nadir of $11 \pm 4 \%$ of the baseline.

To assess whether this monocyte- $T$ cell interaction was unique to the rodent or present also in human cells, three similar studies were conducted using peripheral blood monocytes and T lymphocytes of man. Preincubating human monocytes from peripheral blood with a similar range of insulin concentrations followed by extensive washing and co-mixture with freshly prepared $T$ lymphocytes of the same volunteer subject had a similar effect on specific insulin binding generated after lectin stimulation of the $T$ lymphocytes and tissue culture, with a fall in specific binding to a nadir of $10 \%$ of baseline when the monocytes had been preincubated with $10^{-6} \mathrm{M}$ insulin.

It is possible that the monocytes from preincubated insulin bring to the freshly prepared $\mathrm{T}$ lymphocytes, despite extensive

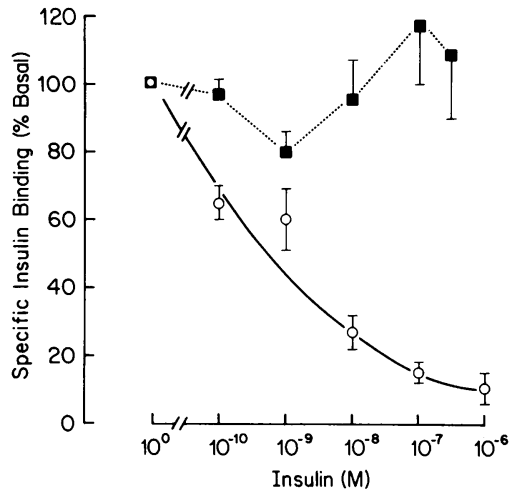

Figure 3. Effect of insulin preincubated with $\mathrm{T}$ lymphocytes or monocytes on activated $T$ lymphocyte insulin receptor binding. ( $A b$ scissa) Concentration of insulin in which rodent immunocompetent cells were preincubated before extensive washing and co-mixing with freshly prepared syngeneic T lymphocytes, followed by provision of activating stimuli. (Ordinant) Specific binding of iodoinsulin to activated $\mathrm{T}$ lymphocytes as a percent of the amount of binding found when no insulin was in the preincubation. (Circles) Insulin preincubation of monocytes followed by monocyte-T cell mixing. (Squares) Insulin preincubation of $\mathrm{T}$ lymphocytes followed by T lymphocyte-T lymphocyte mixing.

washing, enough insulin for the ligand itself to be the signal for $T$ lymphocyte insulin receptor regulation. To test the effect of altering insulin concentrations in the tissue culture environment during the provision of the activating stimulus to the lymphocytes, a series of studies was performed in which freshly prepared human $T$ lymphocytes were placed into tissue culture with from 0 to $10^{-6} \mathrm{M}$ insulin at the time of phytohemagglutinin pulse and harvested at the peak of the lectin response as judged by the incorporation of tritiated thymidine. There was no difference in specific insulin binding to the activated $\mathrm{T}$ lymphocyte in the face of manipulation of insulin in the tissue culture media.

To test the specificity of the preincubation of a ligand with the monocyte cell lineage, additional studies were performed in which human $\mathrm{T}$ or B lymphocytes were obtained and incubated for $24 \mathrm{~h}$ with a similar range of insulin concentrations, as in the monocyte preincubation experiments, and this was followed by extensive washing and co-mixing of these preincubated lymphocytes with freshly prepared $\mathrm{T}$ lymphocytes from the same volunteer in a 10:1 ratio of freshly prepared/preincubated $T$ cells. Phytohemagglutinin was introduced into the culture and the cells analyzed after $48 \mathrm{~h}$. Basal specific binding of insulin was unchanged by preincubating $\mathrm{T}$ or $\mathrm{B}$ cells rather than monocytes with insulin in these studies, $101 \pm 6$ and $110 \pm 14 \%$ of baseline, respectively, over the same dose-response range. The specificity of the ligand-derived signal was confirmed when glucagon preincubation of monocytes did not produce regulatory signals for activation induction of the $\mathrm{T}$ lymphocyte insulin receptor. It is possible that the insulin-directed signal passed to the monocyte regulates $T$ lymphocyte activation in general, and that regulation of the $T$ lymphocyte insulin receptors reported here is a nonspecific consequence of such cell-cell interaction. This interpretation was found to be false in that such regulatory signals had no impact in altering the quantitative appearance of another activation receptor, the interleukin II receptor, on the activated lymphocyte.

One can conclude from these series of experiments that the insulin receptor-bearing monocyte can appreciate the concentration of insulin in tissue culture media and relay this signal to the $T$ lymphocyte in a manner the consequence of which is regulation of the amount of insulin receptor binding induced on the stimulated $\mathrm{T}$ lymphocyte. This function is unique to the monocyte and is generally applicable across several species. 
Manipulation of in vivo ambient insulin concentrationsthe glucose clamp studies

To test the hypothesis further that monocytes read the concentration of ambient insulin and pass this information to $T$ lymphocytes for regulation of activated $\mathrm{T}$ lymphocyte insulin receptor display, a series of euglycemic clamps in human volunteer subjects were performed. The goals of the euglycemic, hyperinsulinemic clamp to create steady-state hyperinsulinemia while maintaining fasting blood glucose were met (Table I, Fig. 4). The 4-h mean blood glucose concentration of $92 \pm 1 \mathrm{mg} / \mathrm{dl}$ is not different from the fasting value, and was maintained with a coefficient of variation for the 4 -h study of $4.2 \pm 0.4 \%$, while raising blood immunoreactive insulin concentrations from $9 \pm 1$ to $61 \pm 1 \mu \mathrm{U} / \mathrm{ml}$. In each normal volunteer, blood was obtained just before the initiation of the insulin and glucose infusions and separated into $T$ lymphocyte and monocyte-enriched populations, respectively. Enough blood was obtained to have available enough $\mathrm{T}$ lymphocytes for each subject to mix with monocytes obtained at 0,2 , and $4 \mathrm{~h}$ of the hyperinsulinemic, euglycemic environment (Fig. 4). These monocytes were bathed in the hyperinsulinemic milieu created by the clamp and then co-mixed with the lymphocytes obtained in the fasting basal state at a ratio of $10 \mathrm{~T}$ lymphocytes: 1 monocyte followed by provision of a lectin-activating stimulus.

At the conclusion of the culture, the $T$ lymphocytes were reserved for analysis of insulin receptor binding. The monocytes obtained over time during the euglycemic clamp had a profound effect on the amount of specific insulin binding to $T$ lymphocytes (Fig. 5). When both monocytes and $T$ lymphocytes were obtained in the basal state and co-mixed with a lectin activator, $4.4 \pm 0.4$ $\mathrm{pg} / 10^{6}{ }^{125} \mathrm{I}$-iodoinsulin was specifically bound to the surface of the activated $\mathrm{T}$ lymphocyte. In contrast, when the monocyte was obtained after $2 \mathrm{~h}$ of hyperinsulinemia and co-mixed with the basal $\mathrm{T}$ lymphocytes, only $2.2 \pm 0.3 \mathrm{pg} / 10^{6}$ lymphocytes were specifically bound on the lymphocyte membrane. Further diminution in the amount of insulin receptor binding on lymphocytes after stimulation was observed when monocytes were obtained after $4 \mathrm{~h}$ of hyperinsulinemia and co-mixed with the basal lymphocytes, $1.3 \pm 0.4 \mathrm{pg} / 10^{6}$ cells. Scatchard analysis of specific insulin binding to $\mathrm{T}$ lymphocytes after co-mixing with monocytes obtained during the 4th hour of the clamp revealed the diminution in specific iodoinsulin binding to activated lymphocytes to be a consequence of a diminished number of measurable receptors. One can conclude from these in vivo experiments that monocytes detect the concentration of ambient plasma insulin and instruct naive lymphocytes in such a manner that there is a reduction in activation-induced lymphocyte insulin receptor display. The monocyte specificity of this reaction was again confirmed when $T$ lymphocytes obtained at 2 and $4 \mathrm{~h}$ of study were mixed with zero time $T$ cells at a ratio of 10:1 followed by stimulation with lectin and measurement of specific insulin binding to lymphocytes. There was no appreciable reduction of iodoinsulin finding after culture with mitogen. In these studies, the well-known effect of hyperinsulinemia on reducing binding to T lymphocytes was not appreciated, since only one-tenth of the co-mixed culture was amenable to direct insulin modulation, while nine-tenths of the cells were freshly prepared and then stimulated.

\section{Discussion}

This laboratory has shown that the insulin receptor on activated T lymphocytes subserves important immunobiologic functions $(4,7,11)$. Its presence permits ligand to maintain the activated state of the lymphocyte when submaximal antigen stimuli are tendered, to quantitatively regulate the amount of cytotoxic $T$ lymphocyte function in the presence of sensitizing target, and to regulate substrate transport for intermediary metabolism on both $T$ and $B$ lymphocytes. Regulation of the display of the insulin receptor on activated $\mathrm{T}$ lymphocytes, then, may be an essential means by which the control of these immunobiologic functions may be accomplished, and thus is an important area for understanding.

Three distinct mechanisms of lymphocyte insulin receptor regulation can now be characterized. Firstly, we and others have shown that antigen or lectin can provide an on-off signal for de novo synthesis of the insulin receptor, the first event of which is translation of nuclear messenger RNA $(12,14,18)$. At first it was thought that this lymphocyte-activating signal provided an all-or-none signal, such that the activated lymphocyte developed a ubiquitous complement for receptors on its cell surface. Subsequent experiments have demonstrated that two additional mechanisms for more exquisite regulation of the number of receptors that will be synthesized in response to lymphocyte activation obtain. Although provision of the ligand to pure cultures of receptor-negative $T$ lymphocytes undergoing antigen stimulation fails to further regulate receptor display, provision of such a ligand to $T$ lymphocytes already bearing their full complement of insulin receptors leads to diminution in the number of measurable surface receptors, initiates "down-regulation" (19). Recently studies from our laboratory have uncovered a third mechanism of receptor regulation related to alterations of ambient insulin in vivo. These studies revealed that circulating receptor-negative $\mathrm{T}$ lymphocytes perceive both chronic and acute alterations in ambient insulin and remember this information in tissue culture $(8,9)$.

One can contrast and compare these mechanisms of membrane receptor display with those extant in other tissues and for other ligand receptor pairs. A regulatory role for antigen for the synthesis of or adjustment in the number of receptors is common on immunocompetent cells and can be paralleled in other model systems, such as that for the interleukin II or transferrin receptors $(1,3)$. The ability of ligand to adjust the number of surface receptors on cells bearing a full complement of these same receptors is a common feature on many cell types for a wide range of model receptor systems (20). The ability of receptor-negative lymphocytes to appreciate the concentration of ambient insulin and adjust at a future time the number of receptors for insulin

Table I. Study Population for Monocyte/T Cell Clamps

\begin{tabular}{llllll}
\hline No. & OI & Fasting [G] & Fasting IRI & Mean clamp [G] & $\begin{array}{l}\text { Mean clamp glucose } \\
\text { coefficient of variation }\end{array}$ \\
\hline & $\%$ & $m g / d l$ & $\mu U / m l$ & $m g / d l$ & $\%$ \\
\hline & $1.10 \pm 0.03$ & $93 \pm 2$ & $9 \pm 1$ & $92 \pm 1$ & $4.2 \pm 0.4$
\end{tabular}

[G], glucose concentration; IRI, immunoreactive insulin; OI, obesity index. 


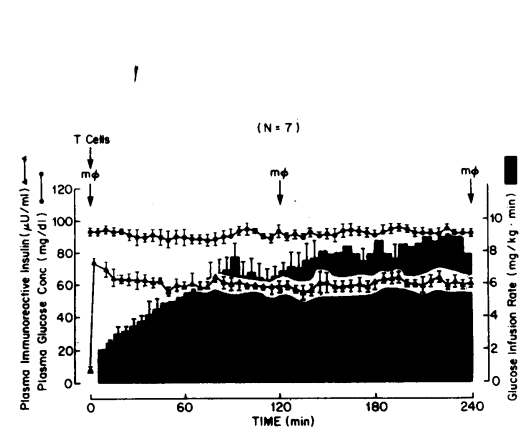

that will appear after activation stimuli are provided may be entirely unique to this model system and tissue.

The means by which the signal generated by ambient insulin can be appreciated by the insulin receptor-negative $\mathrm{T}$ lymphocyte has been the subject of the series of studies described in this manuscript. It is indeed possible that binding of insulin to a small number of insulin receptors on nonstimulated lymphocytes may yet be the regulatory signal for receptor display. This number of insulin receptors would have to be small enough to escape their detection by direct radio ligand binding studies or by measurement of a series of insulin-directed biologic functions on this cell $(4,11)$, but great enough to effect the regulatory message. Direct tests of this hypothesis are not possible until more sensitive means of detecting what must be a very small number of receptors on the cell surface is developed. The inability to test this hypothesis renders it less attractive than alternative explanations of the observed phenomenon.

A more attractive hypothesis to explain ligand-directed regulation of receptor display on the activated $T$ lymphocyte involves the concept of cell-cell cooperation in the interpretation of and processing of afferent signals in the immune system. Indeed, we have previously described a precedent for such interaction of immunocompetent cells in the regulation of insulin

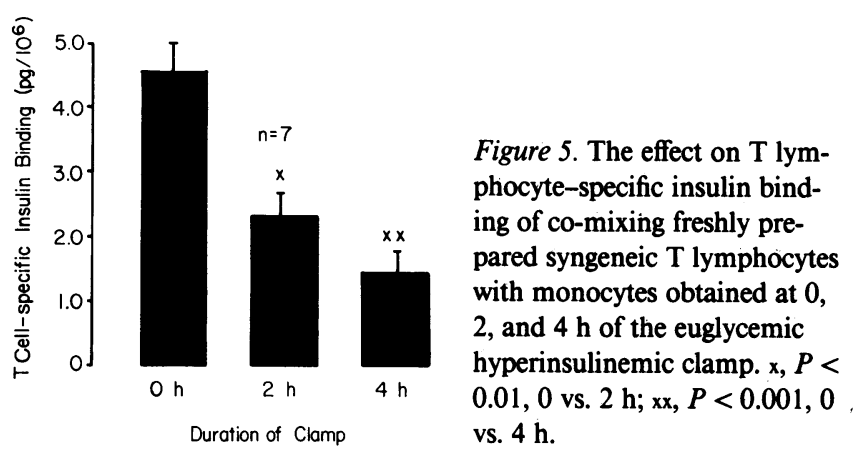

receptor appearance, in that $\mathrm{T}$ and $\mathrm{B}$ lymphocytes interact after $T$ lymphocyte activation for the synthesis of B lymphocyte insulin receptor, a phenomenon that permits insulin to enhance intracellular energy synthesis to meet the increased synthetic demands on the B cells (10). Moreover, such interaction for processing of ligand receptor information follows general rules applicable for interaction of the same cell types for the processing of nominal antigen.

With such precedence available, it seemed attractive to us to explore the hypothesis that the monocyte, a cell which in its unstimulated condition bears a full complement of insulin receptors available for binding of the ligand in circulation, a cell which also initiates afferent recognition of nominal antigen, was the cell responsible for appreciating and passing the insulin signal to the insulin receptor-negative lymphocyte. Studies reported here strongly support this hypothesis. Insulin receptor display is importantly adjusted on activated $\mathrm{T}$ lymphocytes by co-culture with monocytes that had been previously exposed to varying concentrations of insulin within the physiologic range, adjusted either in vitro in tissue culture or in vivo during the human euglycemic clamp. This phenomenon was a unique consequence of monocyte-T lymphocyte interaction, since neither simple manipulation of insulin presented to receptor-negative, quiescent

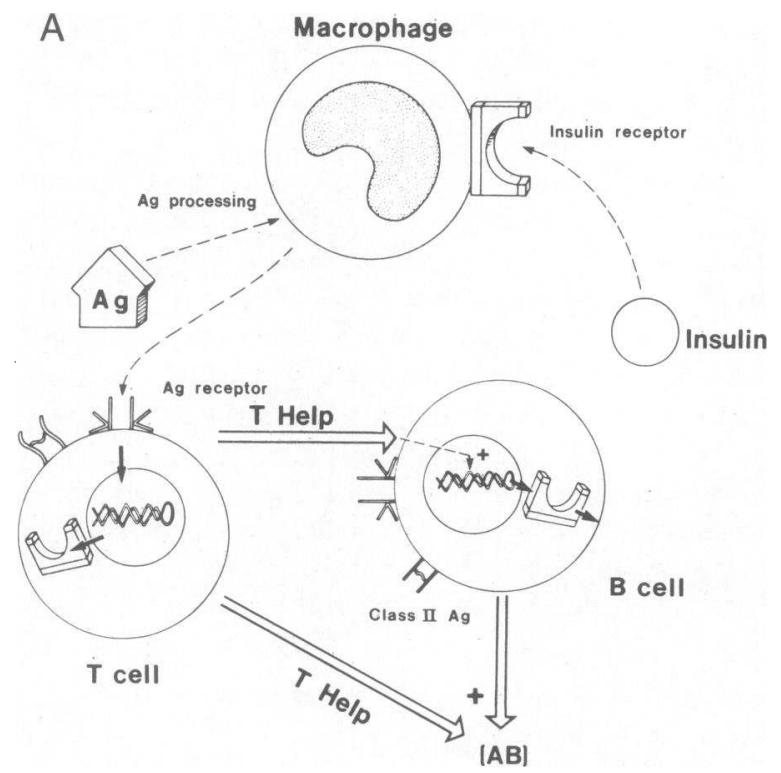

Figure 6. Interaction of the monocyte, the $\mathrm{T}$ cell, and the $\mathrm{B}$ cell for processing of response to antigen $(\mathrm{Ag})$ and to insulin. $(A)$ Antigen initiates the synthesis of $\mathrm{T}$ cell insulin receptors and provides the stimulus for $\mathrm{T}$ helper signals for the synthesis of B cell insulin receptors, while insulin provides regulatory signals that will adjust the quantita-

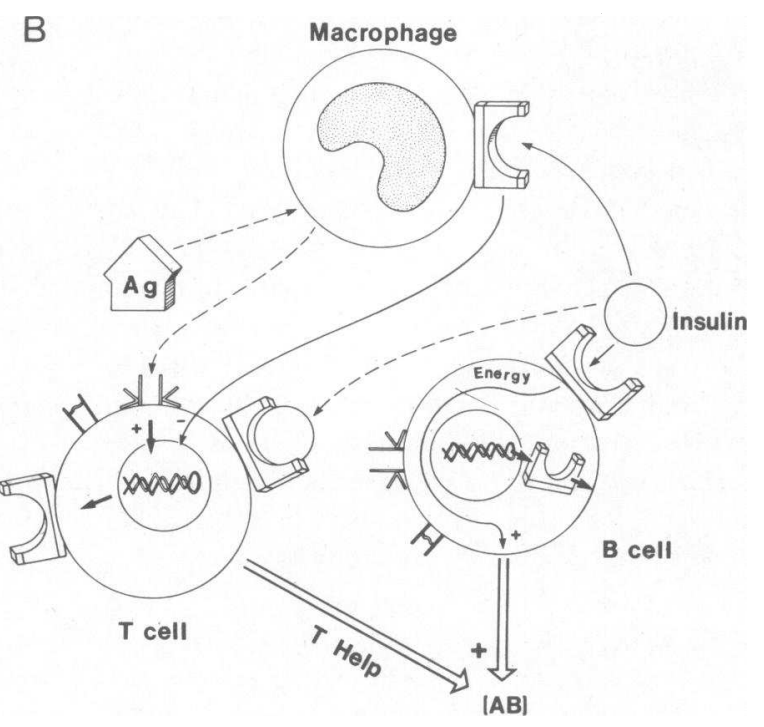

tive nature of the synthetic events. $(B)$ Complement of insulin receptors on the cell surfaces of the $T$ cell and the $B$ cell permit direct ligand binding to adjust the immunobiologic function of both of these cell types, here depicted as $\mathrm{T}$ helper signals and $\mathrm{B}$ cell energy metabolism for antibody production ([AB]). 
T lymphocytes during the activation process nor incubation of other immunocompetent cells with varied insulin concentrations before co-mixing carried the same regulatory signal.

These studies explored the relationship between circulating monocytes and $\mathrm{T}$ lymphocytes. Other antigen-presenting cells (APC), that bear insulin receptors, may also participate in cellcell interaction for regulation of insulin receptors on activated lymphocytes $(21,22)$. The majority of $\mathrm{T}$ lymphocytes attain the insulin receptor during the $G_{1}$ phase of the cell cycle after initiation of an activation signal such as that afforded by antigen (6). There is a tight temporal relationship between initiation of activation, synthesis of, and then disappearance of the insulin receptor. There are periods of time when activated lymphocytes no longer bear the receptor once present on its cell surface (23). Moreover, one can even develop clones of cytotoxic lymphocytes by limiting dilution that can be receptor negative (24), although the majority of these cells are receptor positive. One might then hypothesize that receptor regulation may be afforded by several different pedigrees of antigen-presenting cells to specific subsets of $\mathrm{T}$ cells. The studies reported here, in the least, prove the hypothesis that the circulating monocyte can be one antigen-presenting cell that passes ligand-directed, regulatory signals to polyclonally activated $\mathrm{T}$ lymphocytes.

A holistic theory of the interaction between these $\mathrm{T}$ lymphocytes, B lymphocytes, and monocytes with respect to the insulin receptor and its regulation is depicted in the model found in Fig. 6. Monocytes process nominal antigens and present the antigen to the $T$ lymphocyte, an event that engenders a series of intracellular differentiative events. The $T$ lymphocyte after activation can present "help" to a B cell for B cell synthesis of antibody. Similarly, antigen can stimulate the synthesis of insulin receptors on $\mathrm{T}$ lymphocytes, which permits ligands to enhance lymphocyte function as more efficient effector cells. Binding of insulin to the $T$ lymphocyte insulin receptor augments the $T$ helper phenomenon to allow the B lymphocyte, otherwise unstimulated, to also synthesize an insulin receptor. Presence of the B lymphocyte insulin receptor can then augment B lymphocyte energy metabolism and therefore support or augment B lymphocyte antibody production. Monocytes, therefore, may not only instruct $T$ lymphocytes concerning the nature and presence of antigen, but also concerning the concentration of ambient insulin in the environment in which the $T$ lymphocyte will be stimulated. In the presence of abundant insulin in the environment, monocytes pass controlling signals to $T$ lymphocytes such that, upon antigen-driven insulin receptor synthesis, a reduced number of receptors are synthesized, in effect reducing insulin binding and thereby adjusting the impact afforded by insulin for a given immunobiologic function.

\section{Acknowledgments}

The technical support of Ms. Debra Womble and Ms. Lisa Gagliano, Mr. Kevin Sullivan, the glucose clamp team, and the Clinical Research Center is gratefully acknowledged. Manuscript preparation was ably performed by Ms. Karen Williams with the help of Mr. Ricardo Lopez.

These studies were supported by National Institutes of Health grants R01-AM22150 and M01-RR00633.

\section{References}

1. Robb, R. J., A. Munck, and K. A. Smith. 1981. T-cell growth factor receptors. Quantitation, specificity and biological relevance. $J$. Exp. Med. 154:1455-1479.

2. Galbraith, R. M., P. Werner, P. Arnaud, and G. M. P. Galbraith.
1980. Transferrin binding to peripheral blood lymphocytes activated by phytohemagglutinin involves a specific receptorligand interaction. J. Clin. Invest. 66:1135-1143.

3. Galbraith, R. M., and G. M. P. Galbraith. 1981. Expression of transferrin receptors on mitogen-stimulated human peripheral blood lymphocytes: relation to cellular activation and related metabolic events. Immunology. 44:703-710.

4. Helderman, J. H., and T. B. Strom. 1977. The emergence of insulin receptors upon alloimmune cells in the rat. J. Clin. Invest. 59:338-344.

5. Helderman, J. H., and T. B. Strom. 1978. The specific insulin binding site on T and B lymphocytes: a marker of cell activation. Nature (Lond.). 274:62-63.

6. Helderman, J. H., T. C. Reynolds, and T. B. Strom. 1978. The insulin receptor as a universal marker of activated lymphocytes. Eur. $J$. Immunol. 8:589-595.

7. Helderman, J. H., R. Gruchalla, and L. E. Edwards. 1984. Effect of insulin and transferrin in the maintenance of the activated state of the T-lymphocyte induced by alloantigen. Diabetalogia. 27:99-101.

8. Helderman, J. H., A. Pietri, and P. Raskin. 1983. In vitro control of T-lymphocyte insulin receptors by in vivo modulation of insulin. Diabetes. 32:712-717.

9. Helderman, J. H. 1984. Acute regulation of human lymphocyte insulin receptors. Analysis by the glucose clamp. J. Clin. Invest. 74:14281435.

10. Helderman, J. H. 1983. T cell cooperation for the genesis of B cell insulin receptors. J. Immunol. 131:644-650.

11. Helderman, J. H. 1981. The role of insulin in the intermediary metabolism of the activated thymic derived lymphocyte. J. Clin. Invest. 67:1636-1642.

12. Helderman, J. H., and T. B. Strom. 1979. Role of Protein and RNA synthesis in the development of insulin binding sites on activated thymus-derived lymphocytes. J. Biol. Chem. 254:7203-7207.

13. DeFronzo, R. A., J. D. Tobin, and R. Andres. 1979. Glucose clamp technique: a method for quantifying insulin secretion and resistance. Am. J. Physiol. 237:E214-E223.

14. McGuire, E. A. H., J. H. Helderman, J. D. Tobin, R. Andres, and M. Berman. 1976. Effects of arterial versus venous sampling on the analysis of glucose kinetics in man. J. Appl. Physiol. 41:565-573.

15. Helderman, J. H., D. Elahi, D. K. Andersen, G. S. Raizes, D. Shocken, and R. Andres. 1983. Prevention of the glucose intolerance of thiazide diuretics by maintenance of body potassium. Diabetes. 32:106111.

16. Herbert, V., K. S. Lau, C. W. Gottlieb, and S. J. Bleicher. 1965. Coated charcoal immunoassay of insulin. J. Clin. Endocrinol. Metab. 25:1375-1385.

17. Yalow, R. S., and S. A. Berson. 1960. Immunoassay of endogenous plasma insulin in man. J. Clin. Invest. 39:1157-1175.

18. Kumagai, J.-I., H. Akiyama, S. Iwashita, H. Iida, and I. Yahara. 1981. In vitro regeneration of resting lymphocytes from stimulated lymphocytes and its inhibition by insulin. J. Immunol. 126:1249-1254.

19. Ercolani, L., T. J. Brown, and B. H. Ginsberg. 1984. Tunicamycin blocks the emergence and maintenance of insulin receptors on mitogen activated human T-lymphocytes. Metab. Clin. Exp. 33:309-317.

20. Hollenberg, M. D. 1985. Receptor dynamics and insulin action. In Insulin: Its Receptor and Diabetes. M. D. Hollenberg, editor. Marcel Dekker, Inc., New York. 85-104.

21. Ercolani, L., T. J. Brown, J. C. Hoak, G. L. Fry, and D. D. Nghiem. 1984. Induction and amplification of T-lymphocyte proliferative responses to periodate and soybean agglutinin by human adult vascular endothelial cells. Cell Immunol. 85:225-234.

22. Bar, R. S., S. Stueck, B. Dake, and R. Spanheimer. 1984. Multiplication-stimulating activity (MSA) stimulates proteoglycan synthesis in cultured endothelial cells. Endocrinology 115:2487-2489.

23. Helderman, J. H., and T. B. Strom. 1976. The insulin receptor: a marker of T-cell activation after allograft. Proc. Chr. Dialysis Transplant Forum, 6. 154-158.

24. Braciale, V. L., J. R. Gavin III, and T. J. Braciale. 1982. Inducible expression of insulin receptors on T lymphocyte clones. J. Exp. Med. 156:664-669. 